\title{
TOPICAL APPLICATION OF INSULIN IN THE DIABETIC WOUND ULCER OF FOOT AND ITS COMPARISON WITH REGULAR NORMAL SALINE DRESSING
}

\author{
J. Rajesh Amal Praveen ${ }^{1}$, P. Naresh Kumar ${ }^{2}$
}

${ }_{1}^{1}$ Resident, Department of General Surgery, Sri Venkateshwaraa Medical College Hospital \& Research Centre, Pondicherry. 2Professor \& HOD, Department of General Surgery, Sri Venkateshwaraa Medical College Hospital \& Research Centre, Pondicherry. \begin{abstract}
\section{BACKGROUND}

Diabetic foot ulcers are inevitable in 15\% of diabetic patients even if they follow the diet or control blood sugar level meticulously. The mainstay of treatment for diabetes related foot ulceration is a multidisciplinary team (MDT) approach that includes metabolic control, debridement, offloading/pressure redistribution, vascular control, infection control and seamless integrated wound care. And the ulcer usually is of a chronic type. With regard to topical agents, the effectiveness of topical Insulin is considered valid and effective on wound healing process. The present study is to compare the efficacy of Topical Insulin vs. Normal Saline dressing.
\end{abstract}

\section{MATERIALS AND METHODS}

This is a non-randomised control study. A total of sixty patients with Diabetic foot ulcer were enrolled and the study was done in Department of General Surgery, Sri Venkateshwaraa Medical College Hospital \& Research Centre, Pondicherry from October 2015 to March 2017 for a period of 18 months. Patients were divided into two groups of 30 patients in each, Group A - topical insulin and Group B - normal saline.

\section{RESULTS}

The ulcer size on Day 1 was $48.33 \pm 11.35 \mathrm{~mm}$ and $47.30 \pm 11.30 \mathrm{~mm}$ in Insulin group and Saline group respectively, and the complete healing time achieved in Insulin Vs. Saline group was $30.63 \pm 6.5$ days and $60.47 \pm 23.31$ days respectively with significant $p$ value $<0.0001$.

\section{CONCLUSION}

In the present study, 60 cases were studied comparing the wound dressing of the patient with topical insulin and the normal saline dressing in DFU. The use of topical insulin was found to be safe and effective in patients with diabetic foot ulcers. Results show that topically applied insulin can accelerate wound healing without any systemic side effects.

\section{KEYWORDS}

Diabetic Foot Ulcer, Topical, Insulin, Normal Saline Dressing.

HOW TO CITE THIS ARTICLE: Praveen JRA, Kumar PN. Topical application of insulin in the diabetic wound ulcer of foot and its comparison with regular normal saline dressing. J. Evolution Med. Dent. Sci. 2017;6(95):7020-7025, DOI: $10.14260 /$ jemds $/ 2017 / 1523$

\section{BACKGROUND}

Insulin-An Accelerated Healing Agent.

Wound healing is impaired in patients with diabetes mellitus, and the mechanisms involved in this process are virtually unknown.

Topical Insulin Accelerates Wound Healing in Diabetes by Enhancing the AKT and ERK Pathways.

Studies show that the insulin signalling pathways are unregulated in the wounded skin of normal rats, but in the wounded skin of diabetic animals these upregulations are blunted. However, when the wounded skin of diabetic rats is treated with a topical insulin cream, an acceleration of wound healing occurs, in association with a recovery in the proteins of the insulin signalling pathways.[1]

'Financial or Other Competing Interest': None.

Submission 06-11-2017, Peer Review 08-12-2017,

Acceptance 14-12-2017, Published 23-12-2017.

Corresponding Author:

Dr. P. Naresh Kumar,

Professor \& HOD,

Department of General Surgery,

Sri Venkateshwaraa Medical College Hospital

\& Research Centre, Ariyur, Pondicherry-605102

E-mail:drnk.2011@gmail.com

DOI: $10.14260 / \mathrm{jemds} / 2017 / 1523$

(c) (i) $(2)$
The expression of proteins in early steps of insulin action, i.e., IR/IRS-1, 2/AKT, are increased in the healing tissue of wounds compared to intact skin. AKT has the ability to phosphorylate proteins that regulate lipid synthesis, glycogen synthesis, cell survival, and protein synthesis. $[2],[3],[4]$ Recently, data from different sources demonstrated that AKT activation is considered as an important step for VEGF release in skin wounds, through a post-transcriptional mechanism in keratinocytes,[5],[6] necessary for vascular maturation and angiogenesis during cutaneous wound healing.[7] Therefore, the increase in this signalling pathway observed in the healing skin of wounds might contribute to the process of tissue repair in skin. Insulin stimulation of ERK involves the tyrosine phosphorylation of IRS proteins and/or SHC, which in turn interact with the adaptor protein, Grb2 (growth factor receptor-bound protein-2), recruiting the Son-of-Sevenless (SOS) exchange protein to the plasma membrane for the activation of Ras (member of a large family of small molecular weight GTP-binding proteins).[8] Once activated, Ras operates as a molecular switch, stimulates serine kinase cascade through the stepwise activation of Raf, MEK (protein kinase that activates MAP kinases), and ERK. Activated ERK translocate into the nucleus, where it catalyses the phosphorylation of transcription factors, initiating a transcriptional program that results in cellular proliferation or differentiation. [9] Studies show that protein levels of SHC and 
ERK are increased in the wounded skin, suggesting that the ERK signalling pathway can also play a direct pivotal role in the regulation of cellular growth and differentiation. It is important to emphasise that ERK activation is vital for keratinocyte pro-migratory signalling pathways.[10],,[11],[12],[13],[14]

Normal insulin signalling observed in wounded skin of diabetics might contribute to the impaired wound healing observed as a complication of diabetes. There are several mechanisms which can attenuate insulin signalling in the wounded skin of the diabetic. It is known that elevated glucose level affects insulin signalling by regulating and interfering the expression of several genes, including the insulin receptor gene, at both the transcriptional and translational levels.[15] Hyperglycaemia shown to inhibit insulin action as a result of serine phosphorylation of IRS through a PKC-mediated mechanism, which in turn increases the degradation of IRS proteins.[16],[17]

In accordance with a downregulation of insulin signalling proteins in wound healing of diabetic animals, Goren et al showed that insulin signalling proteins, including IR $\beta$, IRS- 1 , IRS-2, and phosphorylated GSK3 $\beta$ were almost absent in acutely healing skin.[18] It is important to mention that in type 2 diabetes obese animal model, leptin is absent and there is an increase in the level of circulating TNF- $\alpha$. In this regard, previous study shows that the administration of leptin or the infusion of anti-TNF- $\alpha$ reversed the alterations in insulin signalling proteins and improved wound healing. And using a hypoinsulinaemic animal model of diabetes, showed that not only IR/IRSs/PI3k/Akt pathway but also the SHC/ERK pathway are downregulated in the wounded skin of diabetic animal. Study and final report show that the insulin cream can completely restore these alterations.

The molecular mechanisms through which insulin accelerates wound healing in diabetes seem to be variable. The increase in proteins involved in the early steps of insulin action may play a key role, since AKT and ERK have important growth and development effects. Additionally, the use of inhibitors in these pathways reduced the effect of insulin, showing that insulin uses both pathways to increase process of wound healing. At least two important substrates of AKT-GSK3 $\beta$ and eNOS-may have an important role in wound healing.[4],[19] GSK3 $\beta$, when phosphorylated by AKT, has a reduced activity. It was recently studied that mice harbouring a fibroblastspecific GSK3 $\beta$ deficiency exhibit an elevated collagen production, reduction in apoptosis, and acceleration in wound closure.[19] Thus, an increase in GSK3 $\beta$ phosphorylation, and a consequent reduction in its activity, may be one mechanism by which AKT can increase wound healing. AKT can also phosphorylate eNOS and promote in NO production,[20], [21] enhancing blood flow, cell survival, morphogenesis, and angiogenesis, even in the setting of ischaemia.[22],[23] The multitude of AKT substrates and their described effects on various cellular functions may contribute, at least in part, to the beneficial effect of the insulin cream in wound healing, since this insulin topical increases AKT protein expression and phosphorylation in the wounded skin of diabetic rats. Data clearly show that the use of this insulin cream is an efficient manner to activate the AKT and ERK pathways, which are essential in the control of wound healing.

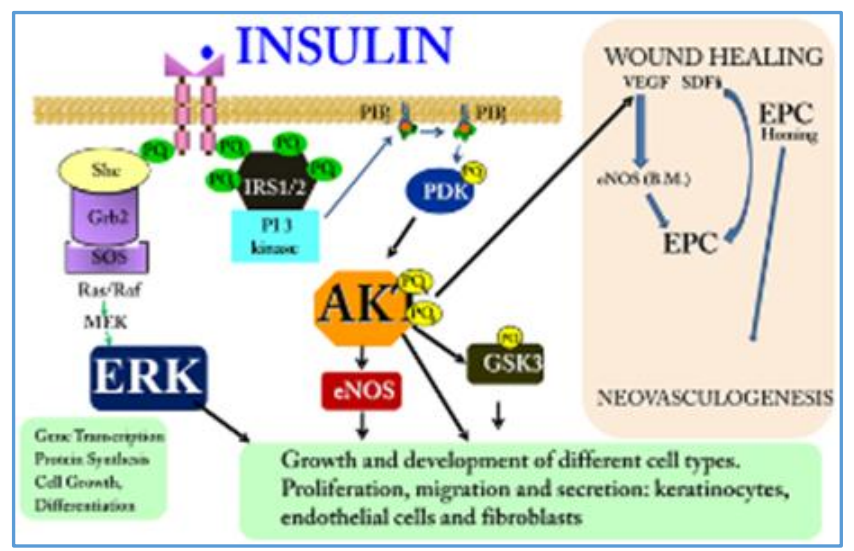

\section{Aims and Objective}

Aim of the Study

To analyse and compare the wound healing of the patient with topical insulin and normal saline dressing in Diabetic foot ulcers.

\section{Objective of the Study}

To determine and calculate the number of days for wound healing.

\section{MATERIALS AND METHODS}

This is a Non-randomised control study. This study was done in Department of General Surgery, Sri Venkateshwaraa Medical College Hospital \& Research Centre, Pondicherry from October 2015 to March 2017.

\section{Collection of Data}

A total of sixty patients with Diabetic foot ulcer were involved. In each group, 30 patients were taken by convenient sampling. Group A (n=30) Patients who underwent dressing with TOPICAL INSULIN

Group B $(\mathbf{n}=\mathbf{3 0})$ Patients Dressed with REGULAR NORMAL SALINE.

\section{Inclusion Criteria}

- Diabetic patients of age 18 years and above.

- Patients having ulcers measuring more than one $\mathrm{cm}$.

- Patients with controlled blood glucose levels.

- Patients with grade 1 and 2 ulcers of Wagner's classification were selected for the study.

\section{Exclusion Criteria}

- $\quad$ Patients with absent peripheral pulses in dorsalis pedis artery, posterior tibial artery, anterior tibial artery.

- Known case of hypersensitive or allergic reaction to the drug used in study.

- X-rays showing features of osteomyelitis.

- Malnutrition and uncontrolled diabetes.

- Patients receiving immunosuppressive therapy.

- Patients who have not given consent for dressing.

In Group A, 5 units of Human Actrapid insulin for ulcer of size $10 \mathrm{~cm}^{2}$ was sprayed daily with an insulin syringe and ulcer was left to dry and then covered with sterile cotton gauze.[24]

In Group B, plain normal saline was used which was one of the standard Procedure for ulcer dressings. 
Wound was washed before dressing with normal saline to remove the debris and measured by using ruler technique. The measurement was performed in millimetres $(\mathrm{mm})$ and in three dimensions i.e. length (L) and width (W) of wounds. Length was measured while considering heel at $120^{\prime}$ clock and toes at 60 'clock position.

The dressing was changed every day. Outcome was measured in terms of wound reduction between the two groups and the day of healing.

\section{Statistical Analysis}

The study data were analysed to evaluate the effect of topical insulin dressing over saline dressing. SSPS software version 23.0 and Microsoft excel software were used in this analysis. Percentages were used to describe qualitative data. Mean \& Standard Deviation were used for quantitative data. Unpaired $t$ test was used to evaluate the results and $P$ value of $<0.05$ is considered significant.

\section{RESULTS}

In the present study, a total of 60 patients of DFU, 30 in Insulin and 30 in Saline group were partitioned. Of that males constituted 24 patients (80\%) and females constituted 6 patients (20\%) in Insulin group. In Saline group, there were 27 male patients (90\%) and females constituted 3 patients (10\%).

\begin{tabular}{|c|c|c|c|c|}
\hline Sex & $\begin{array}{c}\text { Insulin } \\
\text { Group }\end{array}$ & $\begin{array}{c}\text { Insulin } \\
\text { Group } \\
\text { Percentage }\end{array}$ & $\begin{array}{c}\text { Saline } \\
\text { Group }\end{array}$ & $\begin{array}{c}\text { Saline } \\
\text { Group } \\
\text { Percent }\end{array}$ \\
\hline Male & 24 & 80 & 27 & 90 \\
\hline Female & 6 & 20 & 3 & 10 \\
\hline
\end{tabular}

\section{Demographics characteristics of Age wise distribution}

Most of the patients in both Insulin \& Saline group are in age group 56 - 65 years (40\%). The youngest patient in Insulin group was of 41 years and the oldest was of 70 years. In saline group, the youngest was of 44 years and the oldest was of 74 years.

\begin{tabular}{|c|c|c|c|c|}
\hline Age & $\begin{array}{c}\text { Insulin } \\
\text { Group }\end{array}$ & $\begin{array}{c}\text { Insulin } \\
\text { Group } \\
\text { Percent }\end{array}$ & $\begin{array}{c}\text { Saline } \\
\text { Group }\end{array}$ & $\begin{array}{c}\text { Saline } \\
\text { Group } \\
\text { Percent }\end{array}$ \\
\hline $36-45$ & 6 & 20 & 2 & 6.7 \\
\hline $46-55$ & 10 & 33.3 & 9 & 30 \\
\hline $56-65$ & 12 & 40 & 12 & 40 \\
\hline $66-74$ & 2 & 6.7 & 7 & 23.3 \\
\hline
\end{tabular}

Distribution- Demographics, Characteristics of Occupation

Occupation: coolie workers were more in Insulin group i.e. about 17 cases $(56.7 \%)$. And in the Saline group, employees were 12 cases $(40 \%)$.

\begin{tabular}{|c|c|c|c|c|}
\hline Occupation & $\begin{array}{c}\text { Insulin } \\
\text { Group }\end{array}$ & $\begin{array}{c}\text { Insulin } \\
\text { Group } \\
\text { Percent }\end{array}$ & $\begin{array}{c}\text { Saline } \\
\text { Group }\end{array}$ & $\begin{array}{c}\text { Saline } \\
\text { Group } \\
\text { Percent }\end{array}$ \\
\hline Housewife & 2 & 6.7 & 2 & 6.7 \\
\hline Coolie & 17 & 56.7 & 9 & 30 \\
\hline Employee & 7 & 23.3 & 12 & 40 \\
\hline Retired & 4 & 13.3 & 7 & 23.3 \\
\hline
\end{tabular}

Distribution- Demographics, Characteristics of Lower limb ulcer

In the present series of study, right foot was involved more than left foot in both Insulin \& Saline group i.e. 28 cases (93.3\%) and 26 cases (86.7\%) respectively.

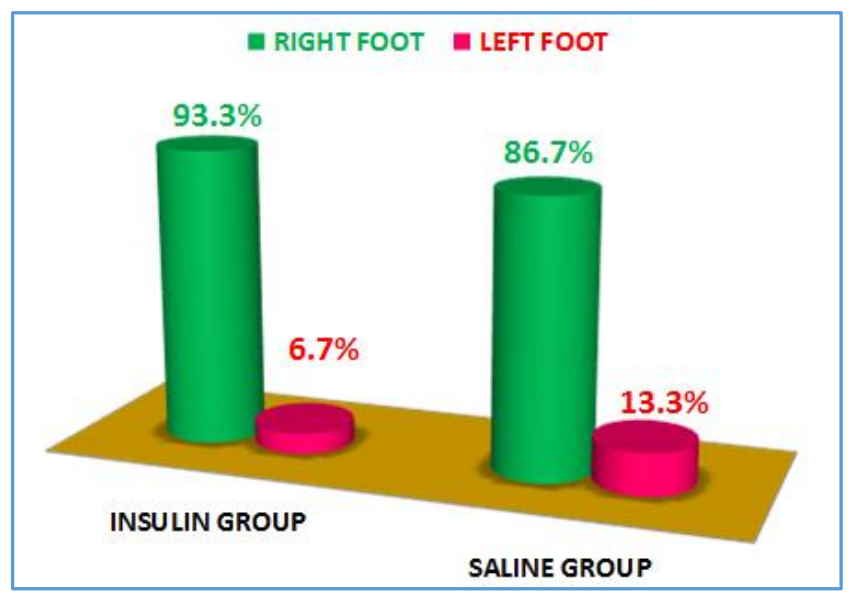

Distribution- Age, Mean and Standard Deviation

The mean age wise distribution in Insulin group was 53.9 years and saline group was 59.2 years showing standard deviation 8.94 and 8.08 respectively, with $\mathrm{p}$ value measuring 0.019 .

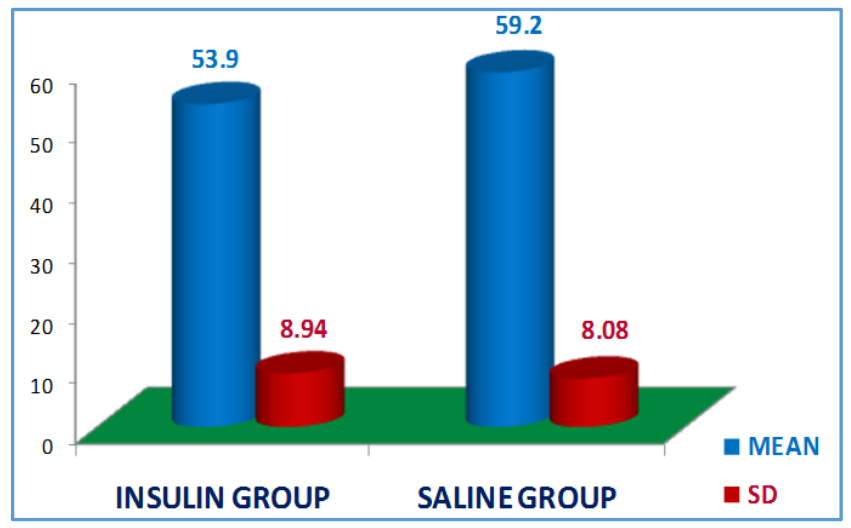

Distribution of Mean and SD in $\mathbf{H b} \%$

The mean Haemoglobin level in insulin group was 11.8\% showing standard deviation 2.04 and in Saline group it was $11.17 \%$ with 1.81 standard deviation. The $\mathrm{p}$-value was 0.156 .

\begin{tabular}{|l|l|l|l|}
\hline Hb & Mean & S.D. & p - value \\
\hline Insulin Group & 11.88 & 2.04 & \multirow{2}{*}{0.156} \\
\hline Saline Group & 11.17 & 1.81 & 0.17 \\
\hline
\end{tabular}

Distribution of Mean and standard distribution in TLC The mean Total Lymphocyte count in insulin group is 7706.67 showing standard deviation 2282.31 and in Saline group 7826.33 with 2665.73 standard deviation. The p value 0.852 . 


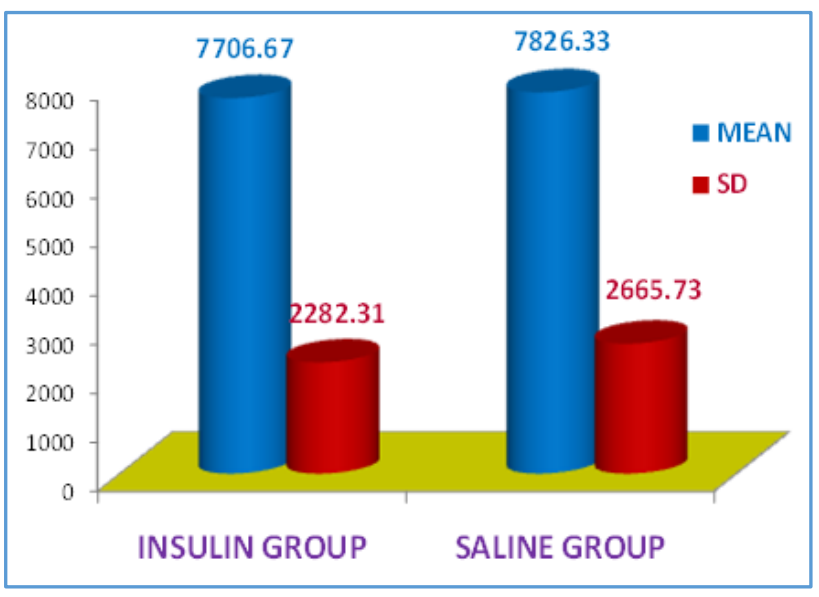

Distribution of Mean and standard deviation in FBS

The mean FBS in Insulin group was $106.77 \pm 29.22 \mathrm{mg} / \mathrm{dL}$ and in Saline group was $105.50 \pm 23.47 \mathrm{mg} / \mathrm{dL}$ with $\mathrm{P}$ value 0.856 .

\begin{tabular}{|c|c|c|c|}
\hline FBS & Mean & S.D. & p - value \\
\hline Insulin Group & 106.77 & 29.92 & \multirow{2}{*}{0.856} \\
\hline Saline Group & 105.50 & 23.47 & \\
\hline
\end{tabular}

\section{Distribution of Mean and standard distribution in PPBS}

The mean PPBS value in Insulin group was $151 \pm 43.43 \mathrm{mg} / \mathrm{dL}$ and in Saline group was $141.4 \pm 37.95 \mathrm{mg} / \mathrm{dL}$ and the $\mathrm{p}$ value was 0.366 .

\begin{tabular}{|c|c|c|c|}
\hline PPBS & Mean & S.D. & p - value \\
\hline Insulin Group & 151 & 43.43 & \\
\cline { 1 - 2 } Saline Group & 141.4 & 37.95 & 0.366 \\
\hline
\end{tabular}

Distribution of Mean and standard deviation in $\mathrm{HbA}_{1 \mathrm{c}}$ The $\mathrm{HbA}_{1 \mathrm{c}}$ in Insulin group was $6.20 \pm 1.28$ and the Saline group was $5.77 \pm 1.04$ and the p value was 0.156

\begin{tabular}{|c|c|c|c|}
\hline HbA1c & Mean & S.D. & p - value \\
\hline Insulin Group & 6.20 & 1.28 & \multirow{2}{*}{0.156} \\
\hline Saline Group & 5.77 & 1.04 & \\
\hline
\end{tabular}

Distribution of Mean and standard distribution in Length In Insulin group, the mean length was $48.33 \pm 11.35 \mathrm{~mm}$ and in Saline group was $47.30 \pm 11.3 \mathrm{~mm}$ with $\mathrm{p}$ value 0.725

\begin{tabular}{|c|c|c|c|}
\hline Length & Mean & S.D. & p - value \\
\hline Insulin Group & 48.33 & 11.35 & \multirow{2}{*}{0.725} \\
\hline Saline Group & 47.30 & 11.30 & \\
\hline
\end{tabular}

Insulin and Saline group among study of Breadth

The mean breadth in Insulin group is $37.4 \pm 7.5 \mathrm{~mm}$ and in Saline group $36.47 \pm 10.94 \mathrm{~mm}$ with p value 0.701

\begin{tabular}{|c|c|c|c|}
\hline Breadth & Mean & S.D. & p - value \\
\hline Insulin Group & 37.40 & 7.5 & \multirow{2}{*}{0.701} \\
\hline Saline Group & 36.47 & 10.94 & \\
\hline
\end{tabular}

Distribution in Insulin and Saline group, Days for Healing The mean of complete wound healing achieved in Insulin group was $30.63 \pm 6.5$ days and Saline group was $60.47 \pm 23.3$ days with $\mathrm{p}$ value $<0.0001$.

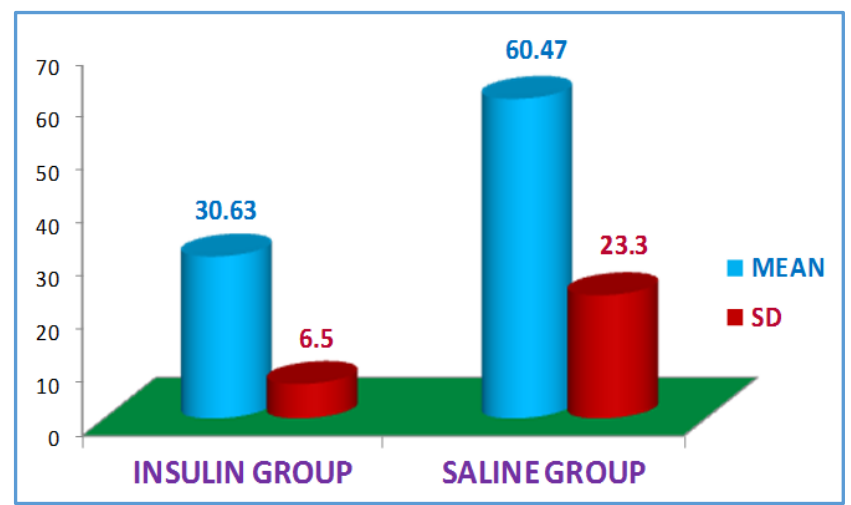

Mean of Insulin and Saline group among study at different time points

The Ulcer size on Day 1 was $48.33 \pm 11.35 \mathrm{~mm}$ and $47.30 \pm$ $11.30 \mathrm{~mm}$ in Insulin group and Saline group respectively, and the complete healing time achieved in Insulin vs. Saline group was $30.63 \pm 6.5$ days and $60.47 \pm 23.31$ days respectively with significant $\mathrm{p}$ value $<0.0001$.

\section{DISCUSSION}

Several studies established the role of insulin as growth factor in stimulating angiogenesis, collagen formation and granulation tissue formation, thus encouraging speedy healing of diabetic foot ulcers. Treatment methods for diabetic foot ulceration often entail burdensome regimes including pressure relief often in the form of a below-knee cast or custom footwear, daily dressing changes and frequent trips to various health professionals. Although these treatment regimens are essential for healing and prevention of further complications, they can last for many months and have a profound effect on activities of daily living and quality of life.

Despite the need for speedy resolution in order to avoid greater complications, it is not uncommon for diabetic foot ulcers to reach a point where progress slows or even stops altogether. Commonly referred to as 'delayed' or 'non-healing' this phenomenon contributes significantly to the chronicity associated with diabetic foot ulcers, and can occur despite appropriate treatment and management of all contributing factors. There are several factors that have the potential to contribute to a delay in wound healing, including poor patient compliance with treatment regimes, poorly controlled glycaemic (blood sugar) levels and poor tissue oxygenation. ${ }^{[25]}$ Also implicated in the delayed or non-healing of diabetic foot ulcers, is the impaired immune response to injury commonly seen in people with diabetes that frequently results in poor, or no progress, after initiation of the inflammatory phase of healing (the initial healing phase involving the arrival of blood cell types and removal of bacteria from the site). This ultimately affects formation of granulation tissue (new tissue containing all the cellular components for skin formation), which is a pre-requisite to epithelialisation or complete skin healing. Findings of our study showed Insulin removes excess exudates from the wound and creates an environment, making a suitable condition for wound healing. Insulin also had better collagen formation with greater reduction in inflammatory cells during healing days resulting in decreased days of healing. Whereas Normal Saline had minimal collagen formation, high grade of inflammation during the healing days with maximum exudates formation resulting in increased days of healing. 
There was no significant difference in age and duration of diabetes of study subjects of both the groups. Most of the patients in both Insulin \& Saline group are in age group 56 - 65 years ( $40 \%)$. In the present series of study, right foot was more involved than left foot in both Insulin \& Saline group. Other biochemical parameters like $\mathrm{HbA}_{1 c}$, FBS, ESR, total lymphocyte count, were non-significant in both the study groups. Total PPBS was lower in normal saline compared to Insulin groups [mean \pm SD; Normal saline vs. Insulin; $141.4 \pm 37.95$ vs. $151 \pm$ 43.4; $\mathrm{p}<0.366$ ]. However, the mean Haemoglobin level in insulin group was $11.8 \pm 2.04$ and in Saline group it was 11.17 \pm 1.81 . The mean total lymphocyte count in insulin group was $7706.67 \pm 2282.31$ and in Saline group it was $7826.33 \pm$ 2665.73. The mean FBS was $106.77 \pm 29.92$ in Insulin group and it was slightly lower in saline group $105.5 \pm 23.47$. The mean $\mathrm{HbA}_{1 \mathrm{c}}$ level was comparatively higher in Insulin study group at $6.20 \pm 1.28$ and in Saline group it was $5.77 \pm 1.04$. Positive family history for diabetes was higher among Insulin group when compared with normal saline group. Among other diabetic complications, almost all the subjects suffered with peripheral neuropathy in both the groups, while hypertension was found to be the second common complication in all the study subjects. There was no statistical difference in complications among both the groups, maximum number of cases had ulcer at their forefoot in both the study groups. There was significant contraction seen in the size of the ulcer in both the study groups depicting the healing process. However, Insulin group depicted better contraction rate. There was statistical difference in initial length and breadth of the wound size among both the groups. However, final length and breadth decreased significantly in both the groups, retaining Insulin group with statistically significant reduction compared to normal saline group. [Mean \pm SD; Final length: Normal Saline vs. Insulin $47.30 \pm 11.3$ vs. $48.33 \pm 11.35$; $=$ 0.725 , Final Breadth: $36.47 \pm 10.94$ vs. $37.4 \pm 7.5$; $=0.701]$.

Statistical significance was observed in healed cases among both the Groups with Insulin group having early recovery, the number of days required for healing was significantly lower than the saline group [Mean \pm SD; Final length: Normal Saline vs. Insulin $30.63 \pm 6.5$ vs. $60.47 \pm 23.33$; $\mathrm{p}=0.00001]$. Number of days of hospitalisation was also less in Insulin group.

\section{Limitations of the Study}

Study limitations include a small sample size. The sample size was chosen in convenience, sample size calculation was not done. Also, a simple method (ruler) was used for wound measurement. Due to the small sample size, outcomes were not controlled by ulcer grade or location. Recommendations for future studies include blinding of control and intervention groups, patient follow-up, comparison of insulin to moistureretentive dressing treatment, and evaluation of patient quality of life and cost-effectiveness of the treatment. These studies also should be conducted in populations with other types of chronic ulcers.

\section{CONCLUSION}

In the present study, 60 cases were studied comparing the wound dressing of the patient with topical insulin and the normal saline dressing in DFU. The use of topical insulin was found to be safe and effective in patients with diabetic foot ulcers. Results show that topically applied insulin can accelerate wound healing without any systemic side effects.

\section{REFERENCES}

[1] Saltiel AR, Pessin JE. Insulin signaling pathways in time and space. Trends Cell Biol 2002;12(2):65-71.

[2] Brem H, Tomic-Canic M. Cellular and molecular basis of wound healing in diabetes. J Clin Invest 2007;117(5): 1219-22.

[3] Kido Y, Nakae J, Accili D. Clinical review 125: the insulin receptor and its cellular targets. J Clin Endocrinol Metab 2001;86(3):972-9.

[4] Schleicher M, Yu J, Murata T, et al. The Akt1-eNOS axis illustrates the specificity of kinase-substrate relationships in vivo. Sci Signal 2009;2(82):ra41.

[5] Goren I, Muller E, Schiefelbein D, et al. Akt1 controls insulin-driven VEGF biosynthesis from keratinocytes: implications for normal and diabetes-impaired skin repair in mice. J Invest Dermatol 2009;129(3):752-64.

[6] Nakai K, Yoneda K, Moriue T, et al. HB-EGF-induced VEGF production and eNOS activation depend on both PI3 kinase and MAP kinase in HaCaT cells. J Dermatol Sci 2009;55(3):170-8.

[7] Somanath PR, Chen J, Byzova TV. Akt1 is necessary for the vascular maturation and angiogenesis during cutaneous wound healing. Angiogenesis 2008;11(3):277-88.

[8] Skolnik EY, Lee CH, Batzer A, et al. The SH2/SH3 domain-containing protein GRB2 interacts with tyrosine-phosphorylated IRS1 and Shc: implications for insulin control of ras signalling. Embo J 1993;12(5):1929-36.

[9] Riess JG. Perfluorocarbon based oxygen delivery. Artificial Cells, Blood Substitute and Biotechnol 2006;34(6):567-80.

[10] Gazel A, Nijhawan RI, Walsh R, et al. Transcriptional profiling defines the roles of ERK and p38 kinases in epidermal keratinocytes. J Cell Physiol 2008;215(2):292-308.

[11] Boulton TG, Nye SH, Robbins DJ, et al. ERK: a family of protein-serine/threonine kinases that are activated and tyrosine phosphorylated in response to insulin and NGF. Cell 1991;65(4):663-75.

[12] Avruch J. Insulin signal transduction through protein kinase cascades. Mol Cell Biochem 1998;182(1-2):3148.

[13] Cheng B, Liu HW, Fu XB, et al. Recombinant human platelet-derived growth factor enhanced dermal wound healing by a pathway involving ERK and c-fos in diabetic rats. J Dermatol Sci 2007;45(3):193-201.

[14] Kim MS, Kim YK, Eun HC, et al. All-trans retinoic acid antagonizes UV-induced VEGF production and angiogenesis via the inhibition of ERK activation in human skin keratinocytes. J Invest Dermatol 2006;126(12):2697-706.

[15] Hauguel-de-Mouzon S, Mrejen C, Alengrin F, et al. Glucose-induced stimulation of human insulinreceptor mRNA and tyrosine kinase activity in cultured cells. Biochem J 1995;305(Pt 1):119-24.

[16] Berti L, Mosthaf L, Kroder G, et al. Glucose-induced translocation of protein kinase $\mathrm{C}$ isoforms in rat-1 fibroblasts is paralleled by inhibition of the insulin receptor tyrosine kinase. J Biol Chem 1994;269(5):3381-6. 
[17] Muller HK, Kellerer M, Ermel B, et al. Prevention by protein kinase $C$ inhibitors of glucose-induced insulinreceptor tyrosine kinase resistance in rat fat cells. Diabetes 1991;40(11):1440-8.

[18] Goren I, Muller E, Pfeilschifter J, et al. Severely impaired insulin signaling in chronic wounds of diabetic ob/ob mice: a potential role of tumor necrosis factor-alpha. Am J Pathol 2006;168(3):765-77.

[19] Kapoor M, Liu S, Shi-wen X, et al. GSK-3beta in mouse fibroblasts controls wound healing and fibrosis through an endothelin-1-dependent mechanism. J Clin Invest 2008;118(10):3279-90.

[20] Dimmeler S, Fleming I, Fisslthaler B, et al. Activation of nitric oxide synthase in endothelial cells by Aktdependent phosphorylation. Nature 1999;399(6736): 601-5.
[21] Fulton D, Gratton JP, McCabe TJ, et al. Regulation of endothelium-derived nitric oxide production by the protein kinase Akt. Nature 1999;399(6736):597-601.

[22] Atochin DN, Wang A, Liu VWT, et al. The phosphorylation state of eNOS modulates vascular reactivity and outcome of cerebral ischemia in vivo. J Clin Invest 2007;117(7):1961-7.

[23] Yu J, de Muinck ED, Zhuang Z, et al. Endothelial nitric oxide synthase is critical for ischemic remodeling, mural cell recruitment and blood flow reserve. Proc Natl Acad Sci U S A 2005;102(31):10999-1004.

[24] Maharaul HH, Pukar MM, Joshi SM. Comparison of Honey and Insulin Dressings in Healing of Chronic Ulcer. IJBR 2015;6(09):638-40.

[25] Greenhalgh DG. The role of apoptosis in wound healing, The International Journal of Biochemistry \& Cell Biology 1998;30(9):1019-30. 